\title{
Simplified Water Requirement Calculators for Fruits and Vegetables
}

\author{
Brent Rowell ${ }^{1,3}$ and Mar Lar Soe ${ }^{2}$
}

\begin{abstract}
Additional Index words. irrigation, drip, microirrigation, trickle, Myanmar, Water Wheel, evapotranspiration, crop coefficient, canopy cover

SUMMARY. New users of drip irrigation in Myanmar had no idea how much water to apply to their crops with drip and could not afford tensiometers or other soil moisture monitoring tools. The concept of a simple paper calculator was born out of their need for an easy-to-use yet inexpensive tool to estimate horticultural crop water requirements. We used a generalized crop coefficient and growth stage approach together with average evapotranspiration (ET) for the vegetable crops "Water Wheel" calculator and a canopy cover approach for the tree fruit calculator. Differences among published crop coefficients are relatively small for a large number of vegetables and single coefficients were used for groups of crops without putting farmers' crops at risk. Vegetable crops were divided into two groups based on whether water requirements during harvest remained the same as for the flowering and fruiting stage or were reduced for the harvest period. A simplified canopy cover approach was used to determine water requirements for perennial fruit, tree, and vine crops. Our faith in the ability of farmers to make their own adjustments gave us confidence to simplify ET-based water requirements and make them available in the form of simple rotating disc calculators printed in color on laminated card stock. The calculators were welcomed by our staff and enabled them to provide reasonably reliable recommendations for new users of drip irrigation. When surveyed, field staff responded that $74 \%$ of farmers they advised followed Water Wheel recommendations. Rough estimates of fruit and vegetable water requirements reached a large number of new drip users in a form they could easily understand, thereby lowering adoption barriers for an unfamiliar technology. This paper describes the Water Wheel concept and design so nonspecialists might develop their own calculators using local climatic data.
\end{abstract}

$\mathrm{O}$ $\mathrm{n}$-farm trials and demonstrations of low-cost drip irrigation systems for fruits, flowers, and vegetables were carried out with hundreds of farmer cooperators by the nonprofit organization Proximity Designs (Yangon, Myanmar) from 2007 to 2009 before launching the country's first locally designed and manufactured drip system in Nov. 2009. Over 20,000 of these small farm systems had been sold by the end of the 2015 dry season (Rowell and Soe, 2015).

From the beginning of these demonstrations, we encountered farmer perceptions that limited adoption of drip. Myanmar farmers seeing-but not yet using-drip irrigation for the first time invariably commented that the system could not possibly supply enough water compared with traditional methods of sprinkler can

${ }^{1}$ Department of Horticulture, N-318 Agricultural Science Center North, University of Kentucky, Lexington, KY 40546

${ }^{2}$ East-West Seed International, No. (40/A), Mya Sabal Road, Ma Yan Gone Township, Yangon, Myanmar

${ }^{3}$ Corresponding author. E-mail: browell@uky.edu. watering or furrow/flood irrigation. Most smallholder farmers trying drip for the first time could not believe that the relatively low water flow observed from emitters could supply needs of the crop.

Local farmers initially had no idea how much water should be applied through a drip system and could not afford simple tensiometers, much less more sophisticated soil moisture monitoring tools or computer software; none had access to personal computers or mobile phones at the time. On-farm demonstrations together with one-on-one discussions of crop water needs and drip application rates became important strategies to address this issue. The idea of a simple paper calculator was born out of these discussions with farmers and their need for an easy-to-use yet inexpensive tool to estimate horticultural crop water requirements. This paper describes concepts and design of two different Water Wheel calculators in enough detail that nonspecialists might develop their own calculators using local climatic data. It is also hoped that this will stimulate further experimentation, discussion, and generate suggestions for improvement.

\section{ET-based water requirements}

Water requirements for various crops have long been estimated using local or regional meteorological records; the most common method uses calculated ET data. ET is defined as the amount of water or moisture that evaporates from the soil surface plus that which is lost through transpiration of the crop (Smajstrla et al., 1997). ET can be used to provide an estimate of the total amount of water needed to grow a crop for a given area. Weather stations commonly estimate water needs by measuring the amount of water evaporating from a wide, shallow pan of a standard size which is located within a well-watered grassy reference surface. Water levels in the pan are measured daily to determine the amount of water that has evaporated; this reference $\mathrm{ET}\left(\mathrm{ET}_{\mathrm{o}}\right)$ is expressed in millimeters or inches per day.

ET is affected by solar radiation, air temperature, wind speed, and relative humidity; historical weather records can be used to calculate estimates of $\mathrm{ET}_{\mathrm{o}}$ (Allen et al., 1998). The Food and Agriculture Organization of the United Nations (FAO) has calculated $\mathrm{ET}_{\mathrm{o}}$ for multiple weather stations in many different countries using the Penman-Monteith equation, which is considered the world standard (Allen et al., 1998); PenmanMonteith-calculated $\mathrm{ET}_{\mathrm{o}}$ is commonly

\begin{tabular}{lllc}
\hline $\begin{array}{l}\text { Units } \\
\text { To convert U.S. to SI, } \\
\text { multiply by }\end{array}$ & U.S. unit & SI unit & $\begin{array}{l}\text { To convert SI to U.S., } \\
\text { multiply by }\end{array}$ \\
\hline 0.4047 & $\mathrm{acre}(\mathrm{s})$ & $\mathrm{ha}$ & 2.4711 \\
0.3048 & $\mathrm{ft}$ & $\mathrm{m}$ & 3.2808 \\
0.0929 & $\mathrm{ft}^{2}$ & $\mathrm{~m}^{2}$ & 10.7639 \\
0.4075 & $\mathrm{gal} / 100 \mathrm{ft}^{2}$ & $\mathrm{~L} \cdot \mathrm{m}^{-2}$ & 2.4542 \\
2.54 & inch $(\mathrm{es})$ & $\mathrm{cm}$ & 0.3937 \\
25.4 & inch $(\mathrm{es})$ & $\mathrm{mm}$ & 0.0394 \\
6.8948 & $\mathrm{psi}$ & $\mathrm{kPa}$ & 0.1450
\end{tabular}


used to estimate water requirements for a wide range of horticultural and agronomic crops. To avoid confusion, we use ET throughout this paper to refer to calculated $\mathrm{ET}_{\mathrm{o}}$. ET data for Myanmar and most other countries are available from the ClimWat 2.0 climatic database (FAO, 2005), which is used by FAO's CropWat software (FAO, 2006, 2009).

\section{Water Wheel concept}

Although it was possible for a few of our senior technical staff to discuss water requirements with individual farmers in Myanmar, it became obvious that to scale up extension efforts, a simpler approach was needed. We needed an easy-to-use tool to help all of our 140 (nonspecialist) field workers quickly determine local water requirements for a variety of horticultural crops. A circular cardboard calculator was envisioned similar to one that had been developed by the Myanmar Agriculture Service to show the cultural requirements for home garden vegetable crops.

The purpose of what we dubbed the "Water Wheel" was to enable field staff to quickly and easily estimate water requirements for the most common fruits and vegetables grown in Myanmar. Field workers could discuss these requirements on the spot before or during installation of a new drip irrigation system, providing farmers with a reliable estimate or starting point to use with drip.

Unknown to us at the time, researchers at Wageningen University in the Netherlands had independently developed and tested a similar calculator based on local ET and crop growth stages; their calculator was tested from 2004 to 2007 on citrus crops (Citrussp.) in Spain and achieved results comparable to those using more sophisticated tools such as FAO's CropWat software (Boesveld et al., 2011). Their Drip Planner Chart has some similarities (but also significant differences) with our Water Wheel and we have shared information and feedback regarding accuracy and ease of use of these tools since early 2009.

\section{Using local climatic data}

The first task for developing a simple calculator was to compile and transform local ET data. Fortunately, monthly average calculated ET values were available from 34 weather stations in Myanmar (FAO, 2005 ). These 30-year averages (196190) were exported to Excel $^{\circ}$ (Microsoft Corp., Redmond, WA) for development of the tables used in the calculators.

We first compared Myanmar weather station locations with the areas where our field staff were working at the time, the majority of whom were within one of three major physiographic regions of the country: 1 ) Lower Myanmar including states and divisions of the Ayeyrawaddy River delta with generally high humidity and rainfall, 2) Upper Myanmar encompassing the "Dry Zone," a region of high temperatures and low annual rainfall, and 3) higher elevations of Shan State with cooler temperatures throughout the year. On the basis of conversations with field staff, we selected from two (Shan State) to seven (Lower Myanmar) weather stations from each region, which were closest to where they were working and appeared to be most representative of the area. Monthly average ETs from these stations, within each region, were averaged to obtain an overall monthly average ET for the entire region. Only the 8 months of the dry season (October to May) were used, resulting in eight average ET values for each of the three regions. These monthly averages were in turn transformed to daily averages by dividing by the number of days of the month under consideration.

All ET data from ClimWat were converted to inches since only English units are widely understood in Myanmar. We assumed a water application efficiency of $80 \%$ recommended for drip irrigation in developing countries by Keller (2002). Daily ET values were divided by application efficiency and the resulting data used to determine water requirements as described below.

\section{Vegetable crop growth stages and crop coefficients}

Myanmar farmers are very much aware that plants require more water as they grow from seedlings to maturity and that some crops require more water than others. Using ET directly for determining water requirements would result in water wasted during earlier growth stages and underwatering for later growth stages. For this reason, correction factors or crop coefficients $\left(\mathrm{K}_{\mathrm{c}}\right)$ are used to adjust ET for a particular crop and its growth stage. Time-averaged $\mathrm{K}_{\mathrm{c}}$ values have been reported for a wide range of horticultural crops and usually range from 0.4 to 1.2 , depending on growth stage (Allen et al., 1998; Dittmar et al., 2015; Doorenbos and Pruitt, 1977; Grattan et al., 1998) (Table 1). Water requirements are estimated by multiplying daily ET by the crop coefficient (i.e., water requirement $=\mathrm{ET}_{\mathrm{o}} \times \mathrm{K}_{\mathrm{c}}$ ).

\section{Growth stages}

Since it is relatively easy to distinguish among major growth stages for most vegetable crops, we used this approach with crop coefficients rather than a canopy cover approach (used for fruit crops as discussed below). Our generic growth stages for vegetables were adapted from those published by FAO (Allen et al., 1998), Florida (Dittmar et al., 2015), and Australia (Qassim and Ashcroft, 2006). FAO and Australia use four stages, whereas Florida uses five stages for vegetable crops. We used only three or four growth stages in the Water Wheel for vegetables, depending on the crop. The fourth stage was used only for crops that benefit from a reduction in water application at harvest. Since drip irrigation was not likely to be used for emerging seedlings in Myanmar, we did not include the period from seeding to germination in our "very small plant" stage below.

Our growth stage names and descriptions were indicative of the crops' physiological state and easily recognized by local farmers and field staff. Growth stages were illustrated with tomato [Solanum lycopersicum (Fig. 1)] and described as follows:

1. Very small plants. Plants after emergence from direct seeding or transplants to $\approx 10 \%$ of the final plant size is reached; plants cover $10 \%$ or less of the soil surface at this stage. This period lasts 2 to 3 weeks for most direct-seeded crops or until $\approx 1$ to 2 weeks after transplanting. For vining crops, this stage lasts until the vines are $\approx 6$ inches long.

2. Rapid growth. This is the period of the most rapid vegetative growth of the young plants. This stage includes plants that are small to medium sized before the full plant 
Table 1. Single (time-averaged) initial, mid-, and late-season crop coefficients $\left(\mathrm{K}_{\mathrm{c}}\right)$ for 25 vegetable crops in subhumid climates and their growth stage means, SD, and CV. Late-season coefficients include all 25 vegetables in the fifth column but only those without water reductions at harvest in the last column (adapted from Allen et al., 1998).

\begin{tabular}{|c|c|c|c|c|c|}
\hline \multirow[b]{3}{*}{ Crop } & \multirow[b]{3}{*}{ Scientific name } & \multirow[b]{2}{*}{ Initial } & \multirow[b]{2}{*}{ Midseason } & \multicolumn{2}{|c|}{ Late season } \\
\hline & & & & All vegetables & No water reduction \\
\hline & & $+--\cdot-\cdot$ & ------- & $\cdots-\mathbf{K}_{\mathbf{c}} \cdots \cdots$ & $-\cdots--\cdot$ \\
\hline Brussels sprout & B. olevacea var. gemmifera & 0.7 & 1.05 & 0.95 & 0.95 \\
\hline Cabbage & B. oleracea var. capitata & 0.7 & 1.05 & 0.95 & 0.95 \\
\hline Carrot & Daucus carota & 0.7 & 1.05 & 0.95 & 0.95 \\
\hline Garlic & Allium sativum & 0.7 & 1 & 0.7 & \\
\hline Lettuce & Lactuca sativa & 0.7 & 1 & 0.95 & 0.95 \\
\hline Onion (dry) & Allium cepa & 0.7 & 1.05 & 0.75 & \\
\hline Onion (green) & A. сера & 0.7 & 1 & 1 & 1 \\
\hline Spinach & Spinacia oleracea & 0.7 & 1 & 0.95 & 0.95 \\
\hline Muskmelon & Cucumis melo & 0.5 & 0.85 & 0.6 & \\
\hline Cucumber & Cucumis sativus & 0.6 & 1 & 0.75 & \\
\hline Pumpkin, winter squash & Cucurbita pepo, Cucurbita maxima & 0.5 & 1 & 0.8 & \\
\hline Zucchini squash & C. реро & 0.5 & 0.95 & 0.75 & \\
\hline Sweet melon & C. melo & 0.5 & 1.05 & 0.75 & \\
\hline Watermelon & Citrullus lanatus & 0.4 & 1 & 0.75 & \\
\hline Table beet & Beta vulgaris & 0.5 & 1.05 & 0.95 & 0.95 \\
\hline Potato & Solanum tuberosum & 0.5 & 1.15 & 0.75 & \\
\hline Sweetpotato & Ipomoea batatas & 0.5 & 1.15 & 0.65 & \\
\hline Green bean & Phaseolus vulgaris & 0.5 & 1.05 & 0.9 & 0.9 \\
\hline Mean & & 0.61 & 1.03 & 0.85 & 0.95 \\
\hline
\end{tabular}

size is reached. It is the growth period before the first appearance of flowers for most vegetable crops or until the time of first fruit setting [melons (Cucumis sp., Citrullus sp.)]. From $10 \%$ to $70 \%$ of the soil surface is covered during this period.

3 . Flowering and fruiting. Plants are flowering and setting fruit and/or have grown to their full size. Fruit or pods are forming and enlarging. For vine crops, most of the ground is covered. This is a very critical period when yield is greatly affected by water available to the plants. This will be the longest and final stage for many crops.

4 . End of season water reduction. Fruit ripening and harvest stage. This stage is used only with certain crops where product quality is improved by reducing water during crop maturity or fruit ripening. For tomato, this begins $\approx 7$ to $10 \mathrm{~d}$ before harvests begin.

\section{Crop coefficients}

Crop coefficients for 25 vegetables used with FAO's initial, mid- and late-season growth stages are shown in Table 1. Lacking a computer or smartphone, these and similar lists are too long to include in a simple tool designed for small farmers in developing countries. Although CropWat generates multiple coefficients by linear interpolation between $\mathrm{K}_{\mathrm{c}}$ values for each growth stage, this also results in too many data than can be used in a simple tool like the Water Wheel. CropWat in its present form is also not user friendly enough for use by most extension workers in developing countries.

FAO's “initial” growth stage (our very small plants stage above) coefficients range from 0.4 for watermelon (Citrullus lanatus) to 0.7 for a large group of nonfruiting crops referred to as "small vegetables"; the overall initial stage mean is 0.61
(Table 1) (Allen et al., 1998). These are relatively high coefficients for small plants and suggest they were developed for high soil surface evaporation, probably with frequent sprinkler irrigation. We chose a smaller single coefficient of 0.4 to use with drip-irrigated vegetable crops at this growth stage; smaller initial stage coefficients $(0.2$ to 0.4$)$ are also recommended for unmulched vegetable crops in Florida (Dittmar et al., 2015).

Most FAO "midseason" (our flowering and fruiting) stage coefficients range from 1.00 to 1.05 with only a few significantly lower or higher: 0.85 for muskmelon ( $\mathrm{Cucu}$ mis melo) and 0.9 for radish (Raphanus sativus) on the low side and 1.15 for potato (Solanum tuberosum), and sweetpotato (Ipomoea batatas) on the high side. The mean coefficient for this entire group of crops is 1.03 with a CV of only $6.6 \%$ (Table 1 ). We chose a higher coefficient of 1.2 , assuming 


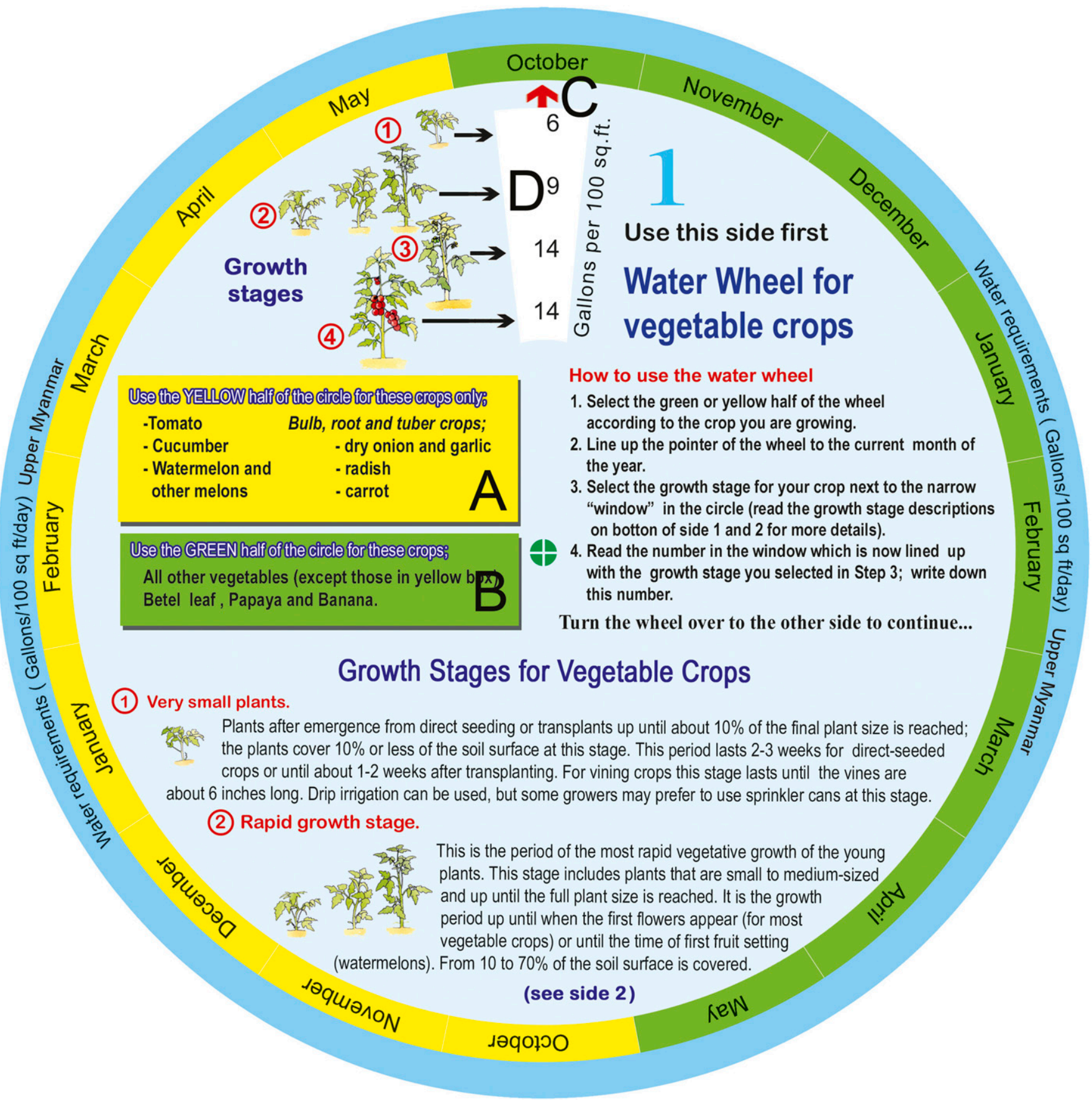

Fig. 1. Side 1 of the Water Wheel for vegetable crops for Upper Myanmar. The wheel consists of an inner stationary disc and outer rotating disc used to determine water requirements per $100 \mathrm{ft}^{2}\left(9.29 \mathrm{~m}^{2}\right)$ based on average evapotranspiration (ET), growth stage, and crop coefficients. Colored boxes on the left side indicate crops with (A) and without (B) water reductions at harvest. The red arrow $(C)$ is lined up with the appropriate month of the dry season to read the water requirement in gallons (D). Crops listed in box B also include betel vine (Piper betle), papaya (Carica papaya), and banana $\left(\right.$ Musa sp.); $1 \mathrm{gal} / 100 \mathrm{ft}^{2}=$ $0.4075 \mathrm{~L} \cdot \mathrm{m}^{-2}$.

maximum canopy cover at this stage with many drip-irrigated vegetable crops grown in densely planted beds in Myanmar. Crops that grow to over $80 \%$ cover in California generally have peak $K_{c}$ values between 1.0 and 1.2 (T. Trout, personal communication). We chose the higher coefficient thinking that the risk of overwatering was preferable to underwatering for new growers unfamiliar with drip irrigation.

Allen et al. (1998) did not report average single coefficients for FAO's "crop development" stage (our rapid growth stage), but assumed a linear relationship between the end of the initial and start of the midseason stage with $\mathrm{K}_{\mathrm{c}} \mathrm{s}$ ranging from 0.50 and 1.15 , depending on the crop. Dittmar et al. (2015) also did not report single coefficients for this period except for vegetables grown using drip irrigation and plastic mulch, which range 
from 0.4 for tomato to 0.6 for muskmelon. Amayreh and Al-Abed (2005) reported 0.65 for drip-irrigated tomato on black plastic for this stage. Other sources used a range between 0.6 and 0.8 (Qassim and Ashcroft, 2006). We chose a single coefficient of 0.8 for our rapid growth stage, erring on the high side at the beginning of this period.

We observed that differences among coefficients for some growth stages are relatively small for a large number of vegetable crops (Table 1 ) and that single coefficients could be used without putting farmers' crops at risk. In addition, the long list of vegetables could be subdivided into two groups based on whether their water requirement during harvest remained roughly the same as in the flowering and fruiting stage or was reduced for the harvest period. Although many vegetables have high water demands throughout harvest, it is best to reduce water for some crops to maintain high fruit or product quality. The latter group includes most fruiting vegetables like tomato, chili (Capsicum annuum), cucumber (Cucumis sativus), and melons together with root, bulb, and tuber crops like potato, sweetpotato, carrot (Daucus carota), radish, garlic (Allium sativum), and onion (Allium cepa) (Allen et al., 1998; Hartz, 1996).

FAO's late-season coefficients were more variable than midseason values because of the reduction in water needs during harvest for some vegetables as described above. Their overall late-season $\mathrm{K}_{\mathrm{c}}$ mean was 0.85 with a $\mathrm{CV}$ of $13.7 \%$ (Table 1). However, when vegetables with late-season water reduction were excluded from this list, the mean coefficient becomes 0.95 (close to the midseason $\mathrm{K}_{\mathrm{c}}$ of 1.03) with a CV of only $3.2 \%$ (Table 1 ).

On the basis of these observations, we considered it safe and reasonable to use single average crop coefficients for two large groups of vegetables: 1) those that received equal amounts of water during mid and late season, and 2) those for which water applications should be reduced during harvest. Erring on the side of overwatering, we used a higher coefficient for our flowering and fruiting stage; this same coefficient was used until the end of harvest for the group of vegetables without any end-of-season water reduction. We used the average coefficients listed in Table 2 in the vegetable crops Water Wheel.

\section{Fruit crop canopy cover estimates}

The crop coefficient is dependent on crop growth, height, and architecture (Allen et al., 1998) and highly correlated with leaf area index and light interception/canopy shading by the crop (Williams and Ayars, 2005; Williams et al., 2003). Lysimeter studies have demonstrated that crop coefficients for grapevines (Vitis sp.) and fruit trees are closely related to midday light interception and canopy cover (Johnson et al., 2000; Williams and Ayars, 2005).

Using estimates of canopy cover is an altogether different approach to determine water requirements in place of growth stages and crop coefficients (Allen and Pereira, 2009; Grattan et al., 1998; Hartz, 1996; Trout and Gartung, 2006). This method relies on a visual estimate of the percentage of the ground shaded by crop foliage or canopy; i.e., the portion of the ground shaded with the sun directly overhead (Fig. 2A and B). We chose this approach to determine water requirements for perennial fruit, tree, and vine crops, thinking that farmers might find this method easier than crop coefficients and growth stages which can be difficult to differentiate for perennial crops.

To estimate canopy cover, extension workers or farmers make a visual estimate of the fraction or percentage of the field shaded from the sun at midday. This fraction then is multiplied by the average ET to determine the daily water requirement. Figure $2 \mathrm{~A}$ is an illustration of canopy cover in plantings where canopies do not merge. Canopy cover can also be estimated by direct measurement for crops in which the foliage touches or merges within the rows by dividing the average width of foliage cover within a row (measure a few representative plants) by the width between bed or row centers (Hartz, 1996; T. Trout, personal communication) (Fig. 2B).

Using the same averaged and efficiency-corrected ET dataset developed for vegetable crops, we constructed new tables using percent canopy cover as correction factors rather than growth stage-based crop coefficients. For the sake of simplicity, only four broad and nonoverlapping canopy cover ranges were used: $5 \%$ to $10 \%, 20 \%$ to $30 \%, 40 \%$ to $50 \%$, and $60 \%$ to $100 \%$. Since we wished to make liberal estimates of water requirements for first-time drip users, the upper limit of the range was used as the actual correction factor with the appropriate ET value. For example, 0.1 is multiplied by daily average ET for crop canopies within the 5\% to $10 \%$ range, 0.3 for canopies in the $20 \%$ to $30 \%$ range, and so on (Table 3). Other researchers have suggested that canopy cover be estimated liberally since peak water demand may slightly exceed ET (Hartz, 1996); most agree that full ET (i.e., $\mathrm{K}_{\mathrm{c}}=1$ ) can be assumed at $60 \%$ to $70 \%$ canopy cover (Smajstrla et al., 1997). We used a liberal correction factor of 1.2 for full cover within the $60 \%$ to $100 \%$ range.

Like the growth stage/crop coefficient method, this approach also has its gaps and simplifications with only four correction factors; however, we expected that growers would extrapolate within and among these ranges. For example, if a grower estimates canopy cover to be only $2 \%$ to $3 \%$, she may decide to use an amount of water lower than the amount recommended for the $5 \%$ to $10 \%$ range. Similarly, if a grower estimates canopy cover to be $15 \%$, he may decide on a water requirement between that indicated for the $5 \%$ to $10 \%$ range and the $20 \%$ to $30 \%$ range. Canopy cover ranges and correction factors

Table 2. Vegetable crop developmental stages used in the Water Wheel and corresponding stages used by FAO together with crop coefficients $\left(K_{c}\right)$ used in the vegetable crops Water Wheel.

\begin{tabular}{llc}
\hline Water Wheel stage & \multicolumn{1}{c}{ FAO stage } & Water Wheel $\mathbf{K}_{\mathbf{c}}$ \\
\hline 1. Very small plants & Initial & 0.4 \\
2. Rapid growth & Crop-development & 0.8 \\
3. Flowering and fruiting & Midseason & 1.2 \\
4. End-of-season water reduction & Late season & 0.8 \\
\hline
\end{tabular}

$\mathrm{FAO}=$ Food and Agriculture Organization of the United Nations. 

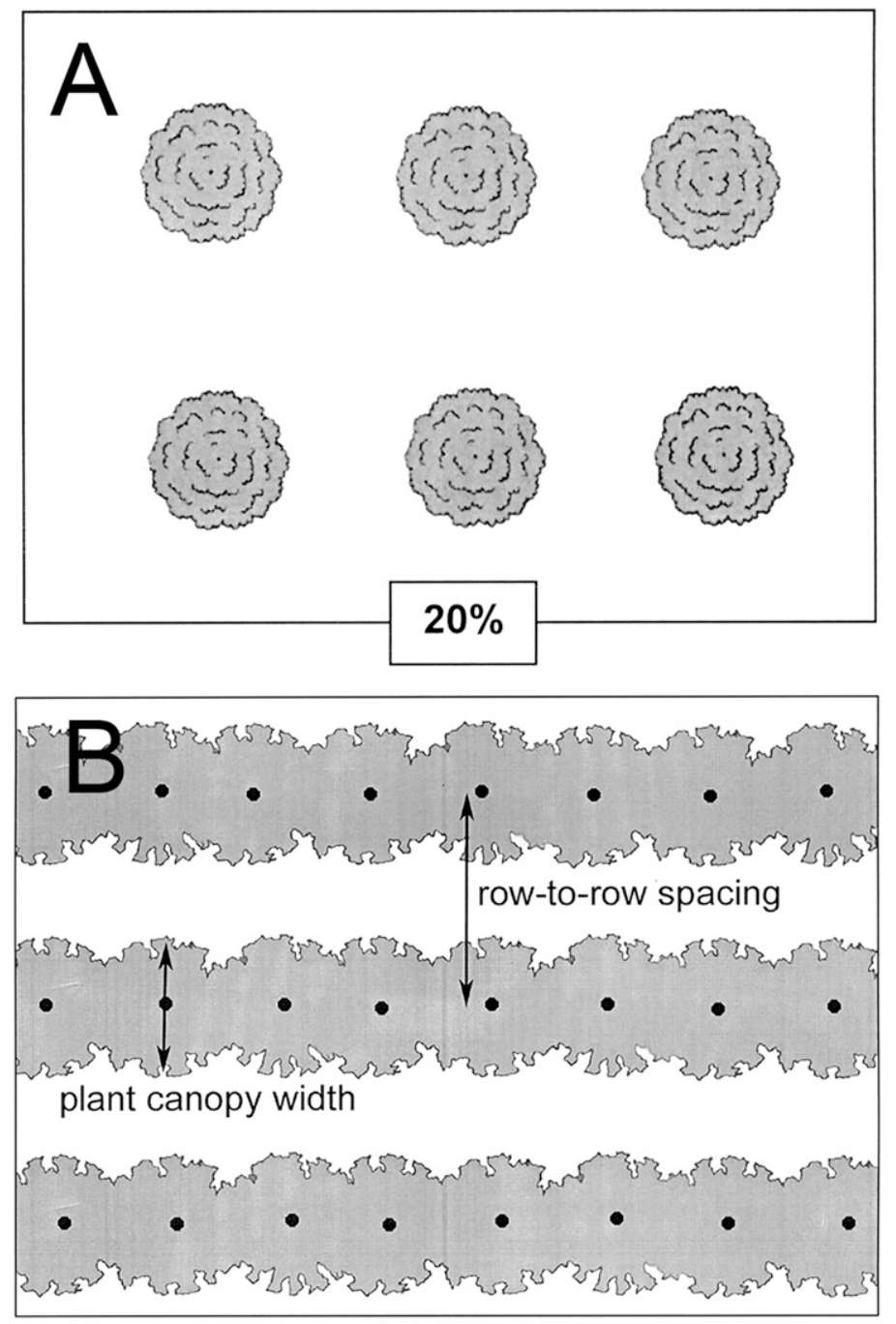

Fig. 2. Percentage of canopy cover for fruit crops can be estimated by visualizing the portion of the field that would be shaded at midday: (A) $20 \%$ cover for crops with canopies that do not merge; (B) percentage of canopy cover can be estimated by dividing the average canopy width by the row-to-row spacing in crops like grape where plants' foliage merges in the rows.

Table 3. Canopy cover ranges and correction factors used in the fruit crops Water Wheel.

\begin{tabular}{lc}
\hline $\begin{array}{l}\text { Canopy cover } \\
\text { range (\%) }\end{array}$ & $\begin{array}{c}\text { Correction } \\
\text { factor }\end{array}$ \\
\hline $5-10$ & 0.1 \\
$20-30$ & 0.3 \\
$40-50$ & 0.5 \\
$60-100$ & 1.2 \\
\hline
\end{tabular}

used in the fruit crops Water Wheel are listed in Table 3 .

\section{Construction and use}

Vegetable crops Water WheEL. Crops were separated into two groups based on whether they benefited from reductions in water for each of the three regions where we were working.

To estimate the daily water requirement, users first determine in which group the crop belongs and select the appropriate green or yellow half of the wheel's perimeter on Side 1 (Fig. 1). Users then point the red arrow at the top of the outer, rotating disc (Fig. lC) to the appropriate month of the dry season on the perimeter of the inner disc. The water requirement in gallons per $100 \mathrm{ft}^{2}$ is read from within the cutout window opposite the appropriate growth stage (Fig. 1D).

After determining the water requirement in gallons per $100 \mathrm{ft}^{2}$, users then turn the disc over to Side 2 (Fig. 3) and point the red arrow at the top of the rotating outer disc (Fig. 3A) to the field size to be irrigated shown in square feet along the inner disc's perimeter (Fig. 3B). The result obtained from Side 1 (in gallons per $100 \mathrm{ft}^{2}$ ) is then located within the column of red numbers to the left of the cutout window (Fig. $3 \mathrm{C})$. The total water requirement in gallons per plot per day appears inside the window adjacent this number (Fig. 3D). The data table used for Side 2 was constructed using simple spreadsheet calculations and arranged in circular form (Fig. 4). Instructions for using the calculator were printed on sides 1 and 2 (Figs. 1 and 3 ). Fortunately, the Water Wheels are much easier to use than to explain.

Fruit crops Water Wheel. Similar procedures were used to determine water requirements using the fruit crops Water Wheel; however, instead of separate wheels for each region, all three regions were combined on a single disc (Fig. 5). Colorcoded sections at the top of the stationary inner disc represent the three regions in Myanmar where Proximity Designs was working. Each of these sections was subdivided into 8 months of the dry season. The result visible in the cutout on Side 1 is expressed as gallons per $100 \mathrm{ft}^{2}$ (Fig. $5 \mathrm{~A})$. To find the water requirement for a given field size, this number from Side 1 is located in one of the two columns adjacent to the cutout on Side 2 (Fig. 6A) and the water requirement per plot is read from within the cutout (Fig. 6B). Note that the numbers in these two columns are in descending order from 


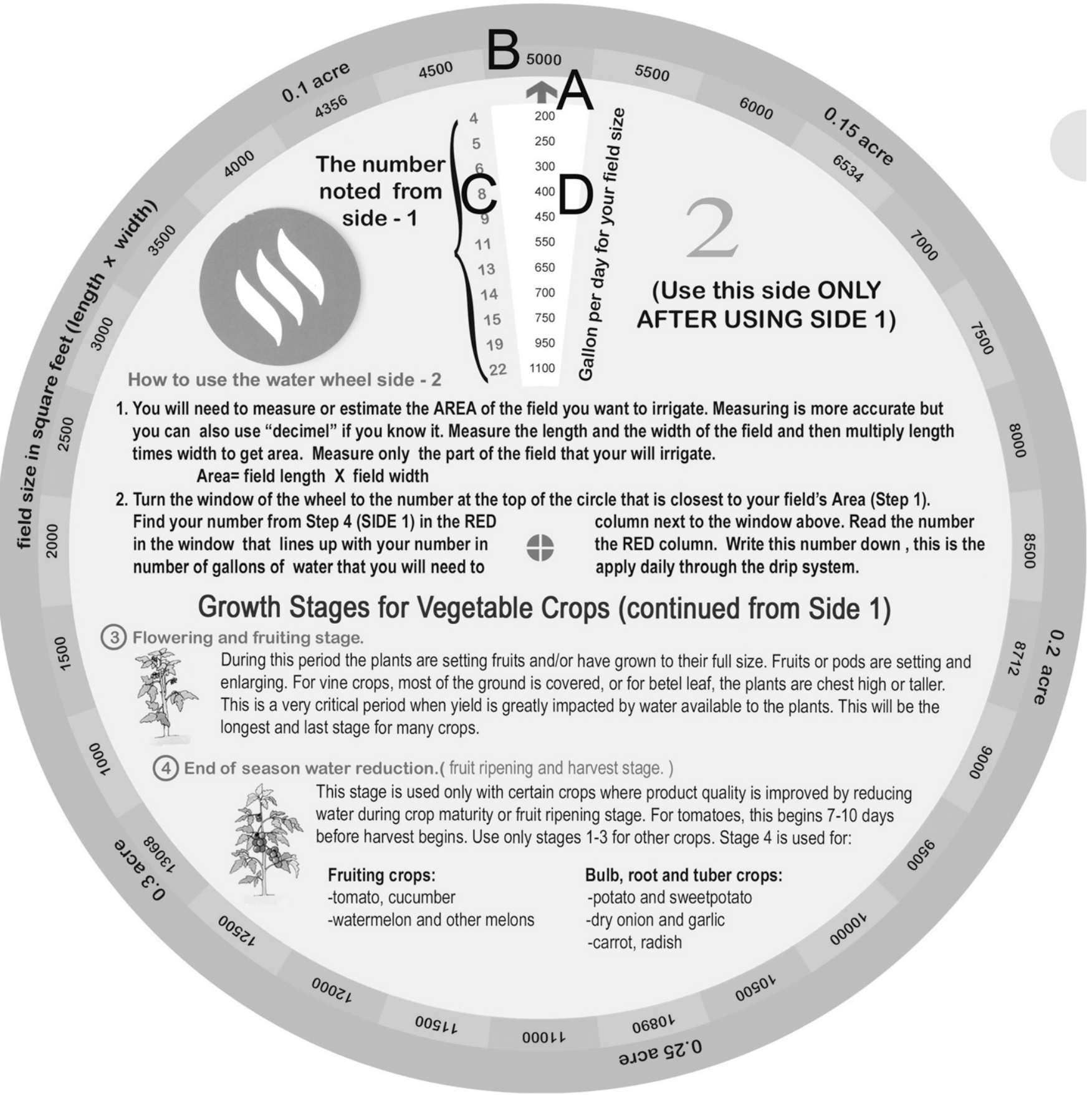

Fig. 3. Side 2 of the Water Wheel for vegetable crops for Upper Myanmar. The wheel consists of an inner stationary disc and outer rotating disc used to convert water requirements per $100 \mathrm{ft}^{2}$ to water requirements per plot. The red arrow (A) is aligned with the appropriate field size (B); the water requirement per $100 \mathrm{ft}^{2}$ from Side 1 is located in the column of red numbers (C) and the water requirement per plot is read in the cutout window $(\mathrm{D}) ; 1 \mathrm{ft}^{2}=0.0929 \mathrm{~m}^{2}, 1 \mathrm{acre}=0.4047 \mathrm{ha}, 1 \mathrm{gal} / 100 \mathrm{ft}^{2}=$ $0.4075 \mathrm{~L} \cdot \mathrm{m}^{-2}$.

top to bottom; this was done so the larger water requirement numbers could be physically accommodated within wider spaces at the top of the cutout.

Instead of descriptions of growth stages, instructions and examples of percent canopy cover are illustrated on the outer rotating discs on both sides of the fruit crops wheel (Figs. 5 and 6). Our extension staff was given a longer, more detailed publication that included good illustrations of canopy cover and discussions of water requirements for specific fruit crops (Rowell and Soe, 2010). This publication also included illustrations and simple instructions for determining water requirements for crops like grape where canopies merge as in Fig. 2B.

An experienced technician at a local print shop developed the circular tables (Fig. 4) and disc layouts using Photoshop $^{\circledR}$ (Adobe Systems, San Jose, CA) and our data tables. A few Burmese language prototypes printed 


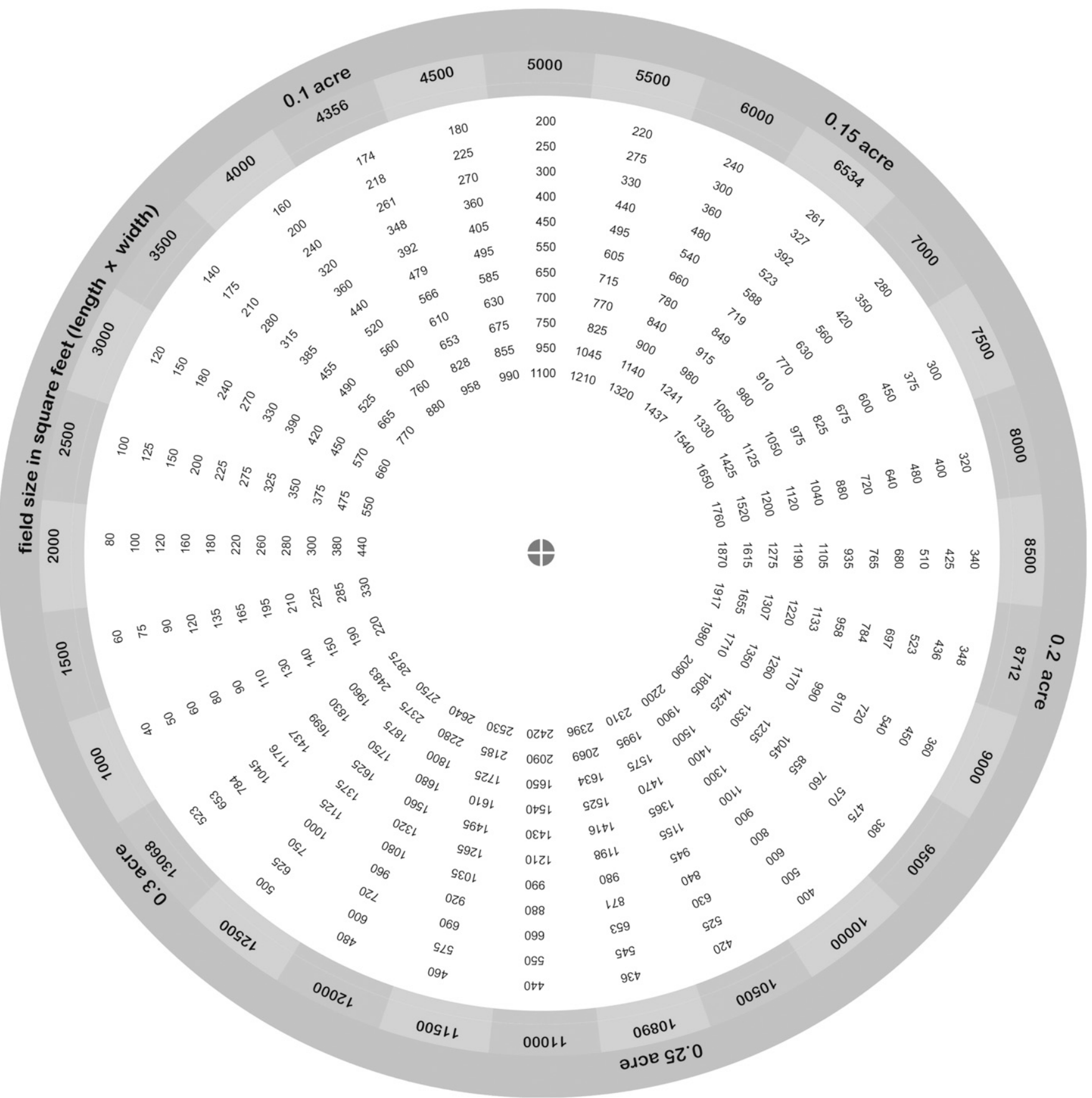

Fig. 4. Circular table of water requirements (gallons per plot) used as the stationary disc on Side 2 of the Water Wheel for vegetable crops for Myanmar; $1 \mathrm{ft}^{2}=0.0929 \mathrm{~m}^{2}, 1$ acre $=0.4047 \mathrm{ha}, 1 \mathrm{gal}=3.785 \mathrm{~L}$.

on ordinary paper were assembled and tested for ease of use among our field staff during an annual in-service training program; minor changes were made to the layout after these tests. All three regional versions of the vegetable crop discs and the fruit crop discs were printed in color on 8 -inch diameter, 0.012-inch-thick card stock laminated for increased durability. In addition to printing, the shop arranged to make the tools required to cut out the discs and rivet them together. Total costs for designing, printing, and assembling were $\$ 1.00$ per wheel.

English versions of the Water Wheels were never printed in quantity and are not commercially available. Water Wheel concepts and designs are not copyrighted or protected in any way so they can be used freely with local ET data in other countries. It is hoped that some of the concepts and simplifications discussed here might be further developed into easy-to-use, farmer-friendly smartphone applications for determining horticultural crop water requirements.

\section{Results and discussion}

User satisfaction. A Water Wheel user satisfaction survey was conducted in 2011 by Proxmity Designs' impact team among 54 extension workers (from 54 townships) 


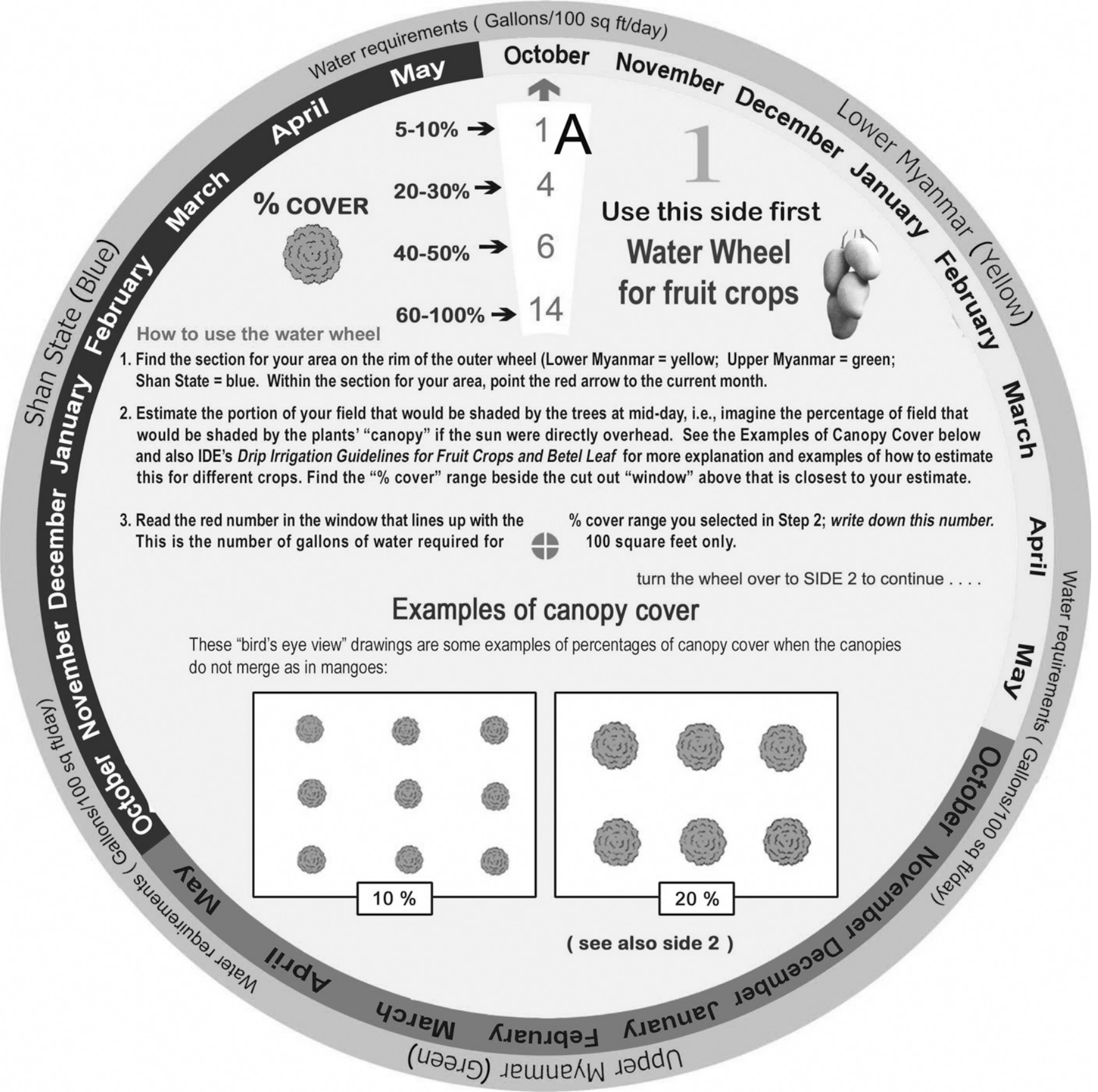

Fig. 5. Side 1 of the Water Wheel for fruit crops for three regions in Myanmar. The wheel consists of an inner stationary disc and outer rotating disc used to determine evapotranspiration-based water requirements per $100 \mathrm{ft}^{2}\left(9.29 \mathrm{~m}^{2}\right) \mathrm{corrected} \mathrm{for}^{2}$ percent canopy cover. Examples of $10 \%$ and $20 \%$ canopy cover are also illustrated. Water requirement is read in the cutout window (A); $1 \mathrm{gal} / 100 \mathrm{ft}^{2}=0.4075 \mathrm{~L} \cdot \mathrm{m}^{-2}$.

from all three regions. Staff reported on their experiences using Water Wheels that year in advising a total of 456 farmers with 763 new drip system installations. In answer to the question "How many farmers that you advised actually followed the Water Wheel recommendations?", $74 \%$ answered "almost all" or "almost all with adjustments according to their experience." Eleven respondents or $20 \%$ reported that about half of the farmers they worked with followed recommendations, whereas only three $(6 \%)$ reported that less than half of the farmers they worked with used Water Wheel recommendations.

When the same extension workers were asked if they thought Water Wheel recommendations were accurate, $91 \%$ felt the recommended amounts were correct, whereas $5 \%$ and $4 \%$ thought the recommended amounts were excessive or insufficient, respectively. Lastly, when asked if the Water Wheels were helpful and useful for their work and program, $87 \%$ reported "very helpful and useful," whereas $13 \%$ reported "somewhat helpful and useful." None of the 54 responded 


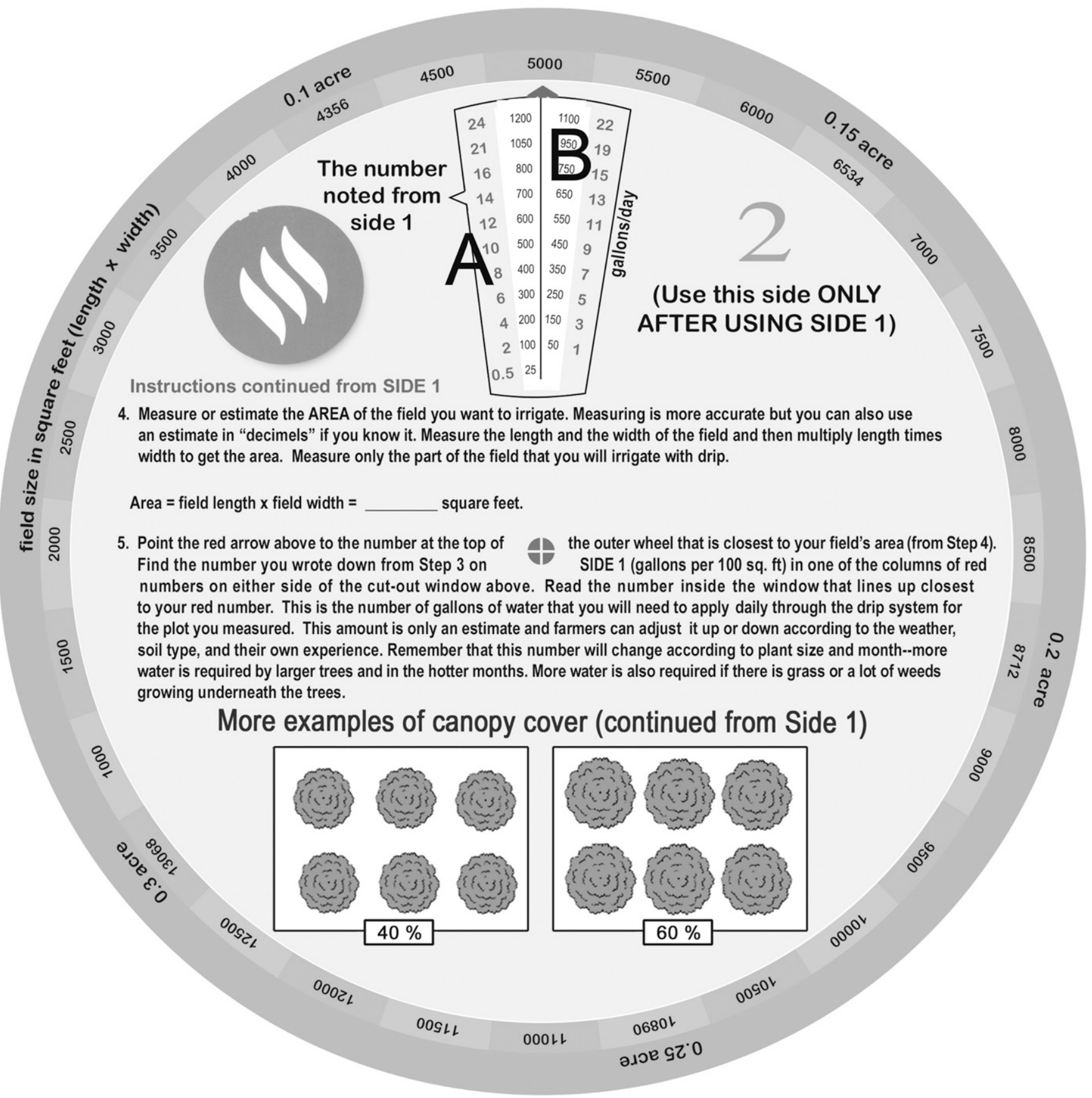

Fig. 6. Side 2 of the Water Wheel for fruit crops for three regions in Myanmar. The wheel consists of an inner stationary disc and outer rotating disc used to convert water requirements per $100 \mathrm{ft}^{2}$ to water requirements per plot. Examples of $40 \%$ and $60 \%$ canopy cover are also illustrated. The red arrow at the top of the cutout window is aligned with the appropriate field size; the water requirement per $100 \mathrm{ft}^{2}$ from Side 1 is located in one of the two columns of red numbers (A), and the water requirement per plot is read in one of the two columns in the cutout window $(\mathrm{B}) ; 1 \mathrm{ft}^{2}=0.0929 \mathrm{~m}^{2}, 1 \mathrm{acre}^{2}=0.4047 \mathrm{ha}$, $1 \mathrm{gal} / 100 \mathrm{ft}^{2}=0.4075 \mathrm{~L} \cdot \mathrm{m}^{-2}$.

with the third choice, which was "not helpful or useful."

Precision versus SIMPLICITY AND EASE OF USE. Although our Water Wheels have not been tested for accuracy against more precise water requirements generated by CropWat, we believe they provided reasonably reliable recommendations for new drip irrigation users in Myanmar. The tool was welcomed by our field staff and gave them extra confidence in answering new drip users' first question: "How much water?" Fortunately, most of these farmers were also using Proximity Designs’ 200-gal collapsible "Water Basket" as a header tank (Fig. 7) which at a height of only $3 \mathrm{ft}$ (equivalent to 1.3 psi water pressure) could irrigate a commercial vegetable plot of up to 0.25 acre (Rowell and Soe, 2015). Growers needed only know how many tanks were used per day to monitor the 


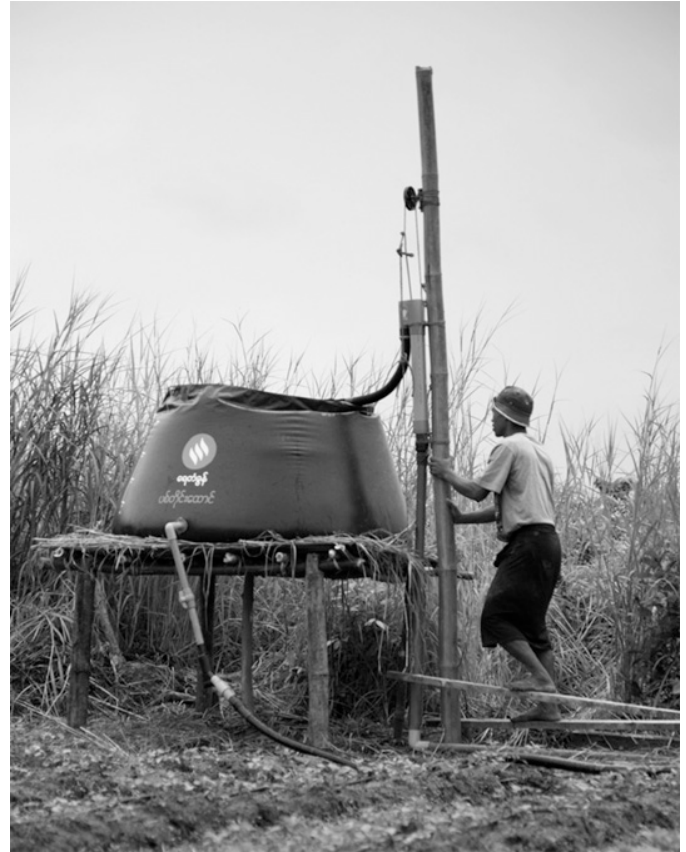

Fig. 7. Proximity Designs' (Yangon, Myanmar) 200-gal (757.1 L) collapsible Water Basket and elevated treadle pump used for drip irrigating up to 0.25 acre (0.101 ha) of commercial vegetables in Myanmar in 2012.

amount of water being applied with drip.

The use of growth stages or selected ranges of canopy cover is of necessity an oversimplification of plant growth and therefore plant water requirements. Growth is more or less continuous, especially during the development or rapid growth stages when water demands are closely associated with the rapidly increasing total leaf surface area. Our simplifications undoubtedly resulted in some overand under-watering, especially if they were followed too literally.

We justified using single crop coefficients for a large number of vegetables after observing only small differences among published coefficients for these crops and after reducing these differences by separating crops into two groups based on their water requirements at harvest. Other losses of precision occurred when fractional water requirements were rounded to whole numbers in the Water Wheel tables and when these were extrapolated for larger field sizes.

Sources of error also included the averaging of ET data as any given day or year can vary considerably from the average and ET at a given location is affected by local microclimate, groundcover, etc. The Water Wheel also did not take into account the chance of dry-season rainfall or differing soil types. However, here again, for the sake of simplicity, we relied on the good judgment and experience of farmers to make adjustments for these variables. The bottom line is that a rough estimate of crop water requirements reached a large number of new drip irrigation users in a form that they could easily understand, thereby increasing their comfort level and lowering adoption barriers for a totally unfamiliar technology.

Most farmers in both developed and less developed countries know better than to blindly follow the recommendations of technical "experts." Experienced farmers have a keen sense of the water needs of their crops regardless of their level of education and will adjust applications up or down until they are satisfied that the crop's needs are being met. It is this faith in the ability of farmers to make their own adjustments that gave us confidence to simplify ET-based water requirements in the form of the Water Wheel calculators. With simplification, it is hoped that good information becomes more accessible to field workers and farmers with very limited or no technical background. We believe that approximate recommendations are better than no recommendations at all.

\section{Literature cited}

Allen, R.G. and L.S. Pereira. 2009. Estimating crop coefficients from fraction of ground cover and height. Irr. Sci. 28:17-34.

Allen, R.G., L.S. Pereira, D. Raes, and M. Smith. 1998. Crop evapotranspiration: Guidelines for computing crop water requirements. Food Agr. Org. United Nations, Irr. Drainage Paper 56.

Amayreh, J. and N. Al-Abed. 2005. Developing crop coefficients for field-grown tomato (Lycopersicon esculentum Mill.) under drip irrigation with black plastic mulch. Agr. Water Mgt. 73:247-254.

Boesveld, H., L.S. Zisengwe, and S. Yakami. 2011. Drip planner chart: A simple irrigation scheduling tool for smallholder drip farmers. Irr. Drain. Syst. 25:323-333.

Dittmar, P., J. Freeman, and G. Vallad (eds.). 2015. Vegetable production handbook of Florida. Florida Coop. Ext. Serv., Gainesville, FL.

Doorenbos, J. and W. Pruitt. 1977. Guidelines for predicting crop water requirements. Food Agr. Org. United Nations, Irr. Drainage Paper 24.

Food and Agriculture Organization of the United Nations (FAO). 2005. ClimWat 2.0 for CropWat. 1 May 2016. <http:// www.fao.org/nr/water/infores_databases_ climwat.html>.

Food and Agriculture Organization of the United Nations (FAO). 2006. CropWat 8.0 for Windows. 1 May 2016. <http:// www.fao.org/nr/water/infores_databases_ cropwat.html>.

Food and Agriculture Organization of the United Nations (FAO). 2009. CropWat: A computer program for irrigation planning and management. Food Agr. Org. United Nations, Irr. Drainage Paper 46.

Grattan, S., W. Bowers, A. Dong, R. Snyder, J. Carroll, and W. George. 1998. New crop coefficients estimate water use of vegetables, row crops. Calif. Agr. 52(1): 16-21.

Hartz, T. 1996. Water management in drip-irrigated vegetable production. HortTechnology 6:165-167.

Johnson, R., J. Ayars, T. Trout, R. Mead, and C. Phene. 2000. Crop coefficients for mature peach trees are well correlated with midday canopy light interception. Acta Hort. 537:455-460. 
Keller, J. 2002. Evolution of drip/micro irrigation: Traditional and non-traditional uses. International Meeting on Advances in Drip/Micro Irrigation, 2-5 Dec. 2002, Tenerife, Spain.

Qassim, A. and B. Ashcroft. 2006. Estimating vegetable crop water use with moisture accounting method. State Victoria Dept. Primary Ind. AG1192.

Rowell, B. and M.L. Soe. 2010. Drip irrigation guidelines for fruit crops and betel vine. Proximity Designs, Yangon, Myanmar.
Rowell, B. and M.L. Soe. 2015. Design, introduction, and extension of lowpressure drip irrigation in Myanmar. Hort Technology 25:422-436.

Smajstrla, A.G., B.J. Boman, D.Z. Haman, F.T. Izuno, D.J. Pitts, and F.S. Zazueta. 1997. Basic irrigation scheduling in Florida. Florida Coop. Ext. Serv. Bul. 249.

Trout, T. and J. Gartung. 2006. Use of crop canopy size to estimate crop coefficient for vegetable crops. Proc. World
Environ. Water Resource Congr., Omaha, NE. p. 1-7.

Williams, L. and J. Ayars. 2005. Grapevine water use and the crop coefficient are linear functions of the shaded area measured beneath the canopy. Agr. For. Meteorol. 132:201-211.

Williams, L., C. Phene, D. Grimes, and T. Trout. 2003. Water use of mature Thompson Seedless grapevines in California. Irr. Sci. 22:11-18. 